\section{Never take a shade again}

Traditionally, in order to provide the optimum in aesthetic composite restorations, it is necessary to spend a considerable amount of time taking an accurate shade match. And, even then, it is sometimes wrong when the patient gets out of the chair! It is also necessary to stock rarely used shades, shades that can go out of date before you have used them up.

Tokuyama have eliminated the cost and inconvenience of both of these problems with the introduction of Omnichroma, the world's first shadeless composite.

Tokuyama's shadeless Omnichroma combines patented 'structural colour' pearl technology with advanced resin expertise so that just one shadeless Omnichroma and Omnichroma Blocker is all you need to replace all 16 Vita shades of any other composite system.

This means that there is no need to shade match ever again so that just one pack saves the time and cost of on average 20 shade matches. Whilst its white opaque uncured appearance makes it clearly visible when packing and carving, it becomes invisible when cured.

Quick and easy to adapt into the cavity, it is extremely quick and easy to polish, again saving valuable time.

For more information about the complete Tokuyama range, including Omnichroma, contact your local Trycare Representative, call 01274 885544 or visit www.trycare.co.uk/ omnichroma.

\section{Protection that tastes good}

When you have patients with problem areas in their teeth that need an extra level of protection, a tooth varnish is an excellent option.

So why not choose a varnish that offers excellent protection and that tastes good as well?

Clinpro White Varnish from $3 \mathrm{M}$ Oral Care is not only a virtually invisible solution, but also an effective combative against hypersensitivity.
Now available in a range of flavours including delicious cherry, mint and melon, Clinpro White Varnish from $3 \mathrm{M}$ is patient friendly and will help them protect their teeth without leaving a nasty taste in their mouth.

Prevention is key - so contact $3 \mathrm{M}$ today. For more information, call 0800 626578 or visit www. 3 m.co.uk/Dental. $3 \mathrm{M}$ and Clinpro are trademarks of the $3 \mathrm{M}$ Company.
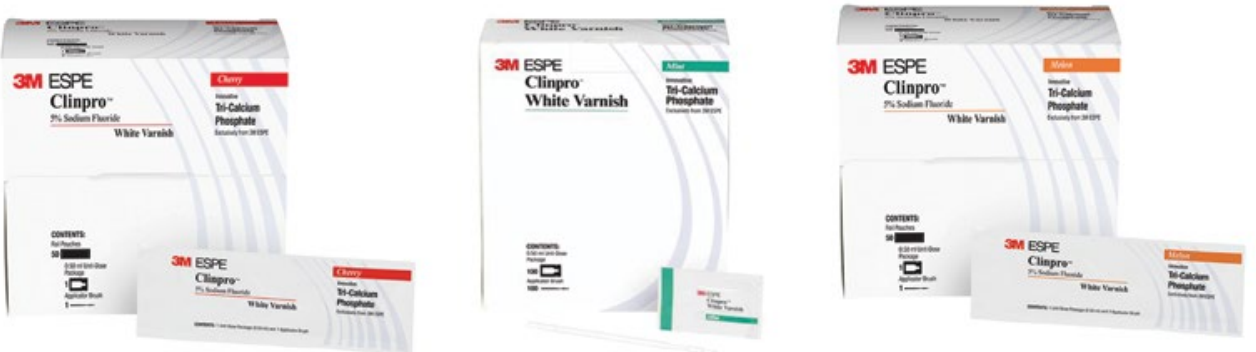

\title{
Protect against sugary snacks
}

Frequent consumption of sugar-rich snacks is associated with increased risk of dental caries. Help patients maintain healthy snacking habits in conjunction with effective oral hygiene by recommending the CS 5460 manual toothbrush from Curaprox.

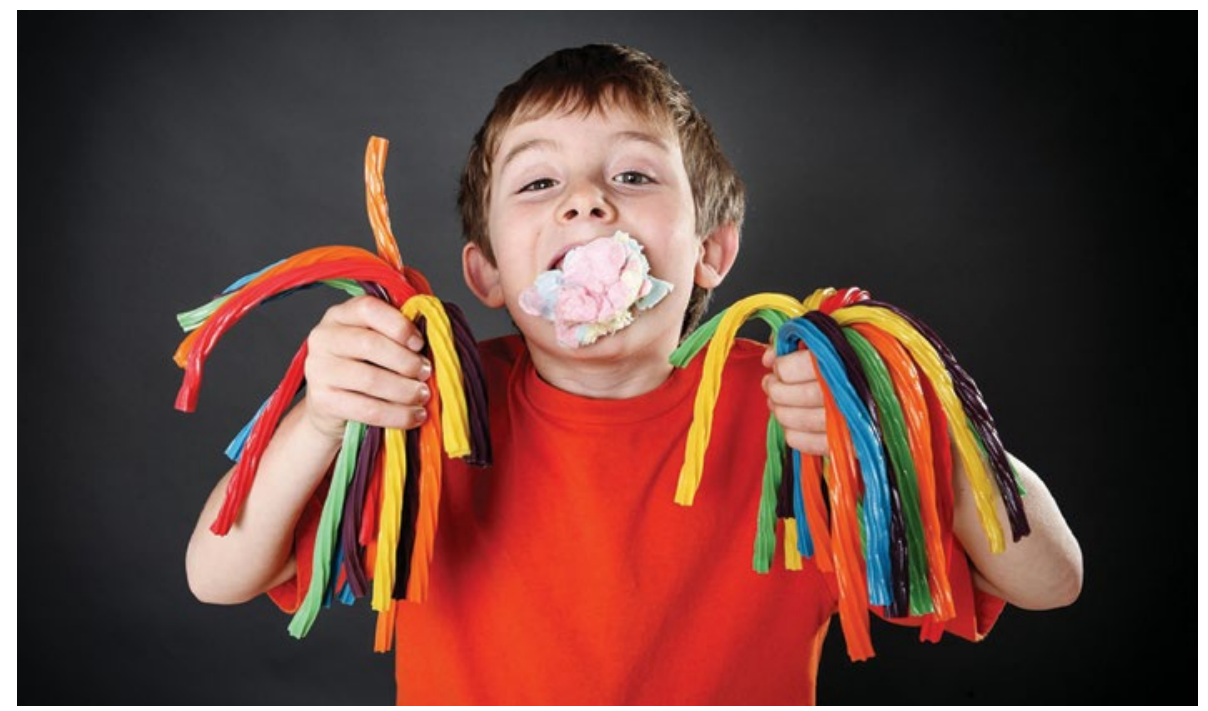

The CS 5460 is distinct from conventional toothbrushes with its octagonal handle and compact brush head, featuring precisely 5,460 ultra-fine CUREN filaments. This creates a durable but extremely soft brushing surface that is ideal for cleaning even the most hardto-reach areas, including the posterior region.

Available in a wide range of exciting colours, the CS 5460 can be used in combination with the CPS Prime interdental brush for optimal results.

For more information call 01480 862084, email info@curaprox.co.uk or visit www. curaprox.co.uk. 